\title{
Phatic Interpretations: Standarisation and Conventionalisation
}

\section{Steve Nicolle \& Billy Clark Middlesex University}

\begin{abstract}
This paper builds on work by Žegarac and Clark (Žegarac and Clark, forthcoming; Žegarac, in press) on phatic communication. Žegarac and Clark define phatic interpretations as interpretations which depend on the recognition of a communicative intention (as defined by Sperber and Wilson 1986 and exploited in their definition of ostensive communication). This definition does not link phatic interpretations directly to social functions but does reflect the fact that phatic interpretations have social effects. The social effects follow from the fact that any act of ostensive communication is, by definition, social. Žegarac discusses how phatic interpretations become standardised and conventionalised. Here we explore the processes of standardisation and conventionalisation in more detail. A first glance at the phenomena suggests an interesting paradox. When a particular linguistic form becomes so frequently linked with phatic interpretations that this usage becomes conventionalised, Žegarac and Clark's definition seems to predict that utterances containing that form will no longer give rise to phatic interpretations (because the interpretation will depend on the linguistically-encoded meaning rather than on the recognition of a communicative intention). We consider an alternative approach to that proposed by Žegarac, which exploits the relevance-theoretic notion of procedural encoding. We show how such an approach might lead to the modification of a prediction of Žegarac and Clark, i.e. the claim that purely phatic interpretations arise only when non-phatic interpretations are not consistent with the principle of relevance.
\end{abstract}




\section{Phatic Interpretations}

Žegarac and Clark (forthcoming) propose the following definitions:

Phatic implication:

A phatic implication is an assumption which depends on the communicative intention alone (perhaps interacting with contextual assumptions, some of which may exploit linguistically-encoded meanings). ${ }^{1}$

Phatic implicature:

A phatic implicature is an ostensively-communicated assumption which depends on the communicative intention alone (perhaps interacting with contextual assumptions, some of which may exploit linguistically-encoded meanings).

Phatic interpretation:

An interpretation is phatic to the extent that it contains phatic implicatures.

Phatic utterance:

A phatic utterance is one which gives rise to, or is intended to give rise to, phatic interpretations.

Phatic communication:

Phatic communication is communication which gives rise to, or is intended to give rise to, phatic interpretations.

On this view, the term phatic is primarily used to describe inferential conclusions which are derived via a particular source, namely the recognition of a communicative intention. Any act of ostensive communication will, by definition, provide evidence for phatic implications. What determines whether particular utterances, or acts of ostensive communication, are phatic is the extent to which they provide evidence for phatic implicatures. This accounts for the intuitions that phaticness is a matter of degree (the more phatic implicatures an utterance gives rise to, the more phatic it is), that the utterance of any linguistic expression could give rise to phatic implicatures (depending on the accessible contextual assumptions), and that certain linguistic expressions are more likely to give rise to phatic implicatures than others. Žegarac and Clark go on to claim that a purely phatic interpretation will only be derived when non-phatic interpretations are not consistent with the principle of relevance; this is a claim to which we will return in the concluding section of this paper. A significant aspect of these definitions is that they do not make direct reference to social functions or social effects. Instead, the fact that phatic communication often has social effects follows from the fact that any act of ostensive communication is, by definition, social. On this account, everyday intuitions about the social functions of particular utterances are much less complex than the cognitive mechanisms which give rise to them. That is, people have intuitions about small talk and the social functions of certain utterances which are less formal and much vaguer than the technical account of phatic communication proposed in Žegarac and Clark (forthcoming), which deals with the cognitive processes involved. 


\section{Standardisation and Conventionalisation}

Žegarac (forthcoming) suggests that phatic communication exists as a social institution (distinct from the cognitive processes described by Žegarac and Clark) and considers two ways in which phatic communication can become institutionalised: standardisation and conventionalisation. Žegarac discusses Bach's (1996) view that standardisation can be understood in terms of the notion of "short-circuited implicature" (for discussion see Searle 1975; Morgan 1978; Bach and Harnish 1979). A "short-circuited implicature" arises when a particular linguistic form has been used frequently in such a way that it gives rise to a particular implicature, or type of implicature. Hearers may then access the intended implicature without going through all the usual processes of interpretation. Groefsema (1992) points out some serious problems with this notion, and Žegarac suggests an alternative, relevance-theoretic, account. He suggests that particular linguistic expressions can become associated not with implicatures but with contextual assumptions. Thus a string such as how are you? may be used in phatic exchanges so often that contextual assumptions required to arrive at phatic interpretations become instantly accessible as encyclopaedic information about the expression. The difference between standardised and conventionalised phatic expressions is that the former retain linguistically encoded meanings which may contribute to the communication of non-phatic information, while the latter do not (this is also the sense in which we will use these terms). Žegarac concludes that standardisation processes have no direct bearing on relevance theory but that they may play a role in the instinutionalisation of phatic communication. He follows Sperber (1996) in suggesting that institutionalisation involves the spread of higher-order representations (very roughly) of the form if you meet a person of equal or lower status who you know and who you haven't seen earlier that day, you may greet them by saying 'how are you?'

Żegarac claims that standardised expressions such as how are you? make available encyclopaedic knowledge about how such expressions are usually understood, in the form of "assumptions about the typical contexts in which particular strings are usually processed for relevance." (We interpret 'contexts' here to mean what Malinowski (1923) termed 'contexts of situation' rather than the more particularised 'contexts of utterance'.) He also states that conventionalised expressions, "like $h i$ and hello, do not contribute to the interpretation of the utterances in which they appear in virtue of their linguistic meaning (either because it has become suppressed, or because they have none), but rather in virtue of people's encyclopaedic knowledge about their use." Žegarac illustrates this as follows: when Mary says hello to Peter, (1) he forms a description of the act of ostension: Mary has said HELLO to me, (2) he accesses some relevant contextual assumptions about how hello is usually understood: "hello" is an informal greeting, and (3) he uses (1) and (2) as premises in deriving the conclusion: Mary has greeted me informally. Because hello is a conventionalised expression, the contextual assumptions used in stage (2) of the utterance interpretation process are immediately accessible to Peter. The only difference between conventionalised expressions and standardised expressions like how are you? on this 
account is that standardised expressions also encode some linguistic meaning in addition to making encyclopaedic knowledge about their use immediately accessible.

If Žegarac's account is correct, these standardised and conventionalised expressions have less in common with most other verbal expressions than with non-verbal modes of expression such as gestures (like handshakes, kisses and salutes) and clothing (for example a dinner jacket or a ball gown makes immediately accessible to an observer encyclopaedic knowledge about the type of event at which such clothes are typically worn). In the case of conventionalised expressions, which according to Žegarac have no linguistic meaning, we are dealing with verbal gestures rather than with linguistic expressions.

\section{Types of Conventionalisation}

In this section we point out a possible alternative approach to Žegarac's account of conventionalisation, drawing primarily on data from grammaticalisation (the development of grammatical markers of, for example, tense, aspect and modality from lexical expressions such as main verbs). This approach draws on the relevance-theoretic notion of procedural encoding.

Žegarac claims that a standardised expression such as how are you? makes available encyclopaedic knowledge about the type of context in which it typically occurs. This is a context in which phatic interpretations are derived (where phatic interpretations, according to Žegarac and Clark (forthcoming) and Žegarac (in press), are interpretations containing implicatures which are inferred from the fact that the speaker has made mutually manifest the intention to communicate with the addressee). When an expression becomes conventionalised on this account, any linguistically encoded meaning becomes suppressed leaving just encyclopaedic knowledge about the type of context in which the conventionalised expression is typically used. A similar account has been given for the type of conventionalisation involved in the development of the grammatical marker will. When the lexical source expression of Modern English will, the Old English main verb willan meaning approximately 'to want', was used with first person subjects, it typically gave rise to implicatures to the effect that the situation or event represented by the rest of the utterance was one which the speaker intended to bring about. From this it could be further inferred that the situation or event in question was yet to occur. Over time will came to indicate future time reference with first person subjects, later generalised to all persons, and more recently to indicate that an associated event is potential in the sense of not yet verified (either because it is yet to occur or for some other reason) (see Nicolle 1997). Drawing a parallel with Žegarac's account of conventionalisation, we could argue that will makes available assumptions about the contexts (in this case 'contexts of utterance') in which it typically occurs, namely that will is used in contexts in which it can be inferred that the situation or event referred to has yet to occur or be verified. The original lexical meaning of willan has been suppressed and no longer exists, and so Modern English will has no linguistically encoded meaning, it merely makes available encyclopaedic knowledge about its use. 
However, recent relevance theoretic accounts of will have not assumed that grammatical markers (will, auxiliary have, etc.) are devoid of linguistic meaning. Instead, it has been suggested that such expressions encode procedural information of different sorts (see Blakemore 1987, 1988, Wilson \& Sperber 1993, Nicolle forthcoming for discussion). ${ }^{2}$ Haegeman (1989: 306) argues that will "signals that the hearer should extend the immediately accessible (present) context for the processing of the proposition and should process the utterance against future propositions"; Klinge (1993: 323) also holds that will is procedural, but argues that it encodes 'potentiality' rather than futurity as the constraint imposed on processing, and Nicolle (1997) argues that will encodes procedural information to represent an associated situation or event as unverified. What all these procedural accounts of will have in common is the claim that will encodes a processing constraint on the way an associated utterance is to be interpreted; only the precise nature of this constraint differs. ${ }^{3}$

A similar account could also be proposed for standardised and conventionalised phatic expressions. On this approach, it could be argued that how are you? encodes procedural information which constrains the inferential processes by which appropriate phatic implicatures are derived. In the following section, we describe some of the possible forms such procedural information might take and discuss some possible modifications such an approach might suggest to predictions which, according to Žegarac and Clark, follow from their own account and the central claims of relevance theory.

\section{Implications of a Procedural Account}

Linguistic expressions which encode procedural meaning may constrain the utterance interpretation process in two main ways. They may directly constrain the inferential computations performed over conceptual representations, or they may "impose constraints on the contexts in which utterances containing them must be interpreted" (Blakemore 1987: 75). Let us look at the standardisation and conventionalisation of phatic expressions from these two perspectives, starting with constraints imposed on contexts. Contexts are constructed on-line as part of the utterance interpretation process, and it has been claimed that some procedural encoding constrains the construction of utterance interpretation contexts (for example, Jucker 1993 argues that the discourse connective well encodes the procedural information that the currently most salient context is not the most relevant for the interpretation of the forthcoming utterance).

What would a procedural account of the expression how are you? look like? Clearly, the constraint on contextual assumptions cannot be too strong. If we suggested, for example, that how are you? encoded procedural information to the effect that the most relevant context for the interpretation of the utterance in which it occurs is that of, say, a conversational opening among friends and acquaintances, we would falsely predict that an occurrence of how are you? intended as a genuine enquiry, for example in a medical 
interview, would be infelicitous. Clearly, it is not (see Coupland, Coupland and Robinson 1992 for a discussion).

An alternative account of the content of any procedural information encoded by how are you? might concern the derivation of phatic implicatures. On such an account, standardised and conventionalised expressions such as how are you? and hi could encode procedural information to the effect that an addressee should begin the processing of an associated utterance by deriving phatic implicatures (that is, assumptions which depend on the communicative intention alone). The criterion of consistency with the principle of relevance states that the utterance interpretation process should cease with the first interpretation tested and found to be consistent with the principle of relevance (giving rise to adequate contextual effects whilst incurring minimal processing effort). Given the procedural account of how are you? and hi outlined above, we would predict that an addressee would first compute phatic implicatures and only go on to derive other, non-phatic, assumptions if a purely phatic interpretation was not consistent with the principle of relevance. In the case of standardised expressions such as how are you? which also encode conceptual information, this means that explicatures (propositions derived from inferentially enriching the conceptual linguistic content of an expression) would only be derived if a purely phatic interpretation of the utterance failed to achieve consistency with the principle of relevance. ${ }^{4}$ This can be illustrated by looking at the interpretation of how are you? given two different sets of contextual assumptions (these invented examples are used for illustration; we will then relate the illustrations to some real data).

(1) Contextual assumptions. Mary is a colleague of the Peter and has not seen Peter since the previous day. They have a good working relationship but are not close friends. Peter has been experiencing back pains recently, but he does not know whether Mary is aware of this.

Mary: How are you?

Peter: Fine. How are you?

An account of example (1) on this approach might say that Mary's utterance of the standardised expression how are you? conveys procedural information which instructs Peter to derive phatic interpretations without first having to compute any non-phatic assumptions (implicatures or explicatures). Peter does not even consider that Mary may have found out about his back pains, since a purely phatic interpretation yields adequate contextual effects given the available contextual assumptions.

(2) Contextual assumptions. Jane is a doctor to whom Peter has come for advice about his back pain. The setting is Jane's surgery. Jane: How are you?

Peter: Well, I've been having problems with my back... 
In this scenario, this approach might say that Peter judges that Jane's greeting does not yield adequate contextual effects if only phatic implicatures are derived. He therefore develops the conceptual information also encoded by how are you? to arrive at an interpretation in which Jane's utterance is intended to be understood as an invitation to Peter to talk about his medical problems.

The initial Well, ... of Peter's reply is interesting. We mentioned above that Jucker (1993) has argued that well indicates that the currently most salient context is not the most relevant for the interpretation of the forthcoming utterance. According to either Žegarac's account or the procedural account suggested above, the context created by an utterance of how are you? typically includes many phatic implicatures. By prefacing his reply with well, Peter indicates that such a context is not sufficient for the optimally relevant processing of his forthcoming utterance. Well is common in naturally occurring data also. Coupland, Coupland and Robinson (1992) recorded the responses of elderly people in a social club who were interviewed about their experiences of health care (the respondents knew the topic of the interview and were told that the interviewer was not a health specialist). Each interview began with the interviewer uttering how are you? "said smiling and uniformly without any clear primary stress" (Coupland et al. 1992: 220). Nine of twenty seven reported responses which were not purely phatic were introduced by well (one respondent uttered eleven initial wells). This is what we would expect given that an utterance of how are you? encourages the addressee to derive a large number of phatic implicatures, but also encodes additional information. If a purely phatic interpretation of how are you? is not optimally relevant to an elderly respondent, but she or he suspects that the interviewer may have intended it to be interpreted purely phatically, this assumption may be conveyed by prefacing a response in which the respondent describes various medical conditions with the discourse connective well. A typical response which suggested a phatic interpretation was oh I'm fine thank you; typical responses suggesting non-phatic interpretations were: Well (.) up and down like you know [which contained 11 initial wells]; Well I'm not bad; and Well not very well I've just had a bad fall (examples from Coupland et al. 1992: 221-224).

This account suggests a possible modification to one of the central claims of Žegarac and Clark (forthcoming). Žegarac and Clark proposed that every utterance may give rise to phatic implicatures, since a phatic implicature is an ostensively-communicated assumption which depends on the communicative intention alone, and an utterance is, by definition, an act of ostensive communication. The intuition that phaticness is a matter of degree arises from the fact that different utterances provide differing amounts of evidence for phatic implicatures. Žegarac and Clark also claimed that a purely phatic interpretation will only be derived when non-phatic interpretations are not consistent with the principle of relevance, that is, when no non-phatic interpretation yields adequate contextual effects. What our discussion here suggests, however, is that in the case of standardised and conventionalised phatic expressions phatic implicatures are the first to be inferred, either because the appropriate contexts are made immediately accessible (as Žegarac claims) or because such expressions encode procedural information to the effect that an addressee should begin the utterance interpretation process by deriving phatic implicatures (as we have 
tentatively suggested). In the case of standardised expressions, which also encode conceptual information, we suggest a converse principle to the general claim proposed in Žegarac and Clark (forthcoming): when a standardised expression is processed, non-phatic interpretations should only arise when purely phatic interpretations are not consistent with the principle of relevance.

\section{Conclusion}

Our tentative discussion here contains some notable gaps. Perhaps the most significant of these is that we have presented no detailed arguments for or against procedural accounts of standardisation and conventionalisation. Furthermore, we have not explored in detail the potentially paradoxical notion that a linguistic expression could encode an instruction to develop a phatic interpretation of an utterance containing it. We hope, though, that we have shown that Žegarac and Clark's work raises interesting and non-trivial questions about linguistic semantics, pragmatics and relevance theory.

\section{Notes}

1. "Depends on" is to be understood in a technical sense here, where "depends on X" means "results from an inferential process which takes $\mathrm{X}$ as a premise."

2. Procedural encoding contrasts with conceptual encoding, which as its name suggests is concerned with the linguistic encoding of concepts (see Sperber and Wilson (forthcoming) for a discussion of the relation between words and concepts). Procedural encoding, on the other hand, is concerned with the inferential computations performed over concepts.

3. In the case of will, previously encoded conceptual information (the sense of 'desire' encoded by $\mathrm{OE}$ willan) has been lost, but in other expressions, such as be going to, Nicolle (forthcoming) argues that conceptual and procedural encoding are both encoded.

4. It could be argued that this begs the question of how an addressee knows which of the two types of information encoded by a standardised expression (conceptual and procedural) to recover first. Nicolle (forthcoming) argues that since the purpose of procedural information is to reduce inferential processing effort, it should always be recovered first, and that additional conceptual information will only be recovered if an interpretation based purely on procedural information fails to achieve adequate contextual effects. Another account might suggest that inferences starting from the conceptual and the procedural meaning are performed simultaneously.

\section{Works cited}

Bach, Kent. "Standardisation Revisited." Pragmatics: Critical Assessment. Ed. A. Kasher. London. Routledge, 1996.

Bach, Kent and Robert M. Harnish. Linguistic Communication and Speech Acts Cambridge Massachusetts: MIT Press, 1979. 
Blakemore, Diane. Semantic Constraints on Relevance. Oxford: Basil Blackwell, I987.

"'So' as a Constraint on Relevance." Mental Representations: The Interface Between Language and Reality. Ed. R. M. Kempson. Cambridge: CUP, 1988. 183-195.

Coupland, Justine, Nikolas Coupland and Jeffrey D. Robinson. "How are you?": Negotiating Phatic Communion." Language in Society 21 (1992): 207-230.

Groefsema, Marjolein. “Can you pass the salt?'A Short-circuited Implicature." Lingua 87 (1992): 103-135.

Haegeman, Liliane. "Be going to and will: A Pragmatic Account." Journal of Linguistics 25 (1989): 291-317.

Jucker, Andreas H. "The Discourse Marker well: A Relevance-theoretical Account." Journal of Pragmatics 19 (1993): 435-452.

Klinge, Alex. "The English Modal Auxiliaries: From Lexical Semantics to Utterance Interpretation." Journal of Linguistics 29 (1993): 315-357.

Malinowski, Bronislaw. "The Problem of Meaning in Primitive Languages." Supplement to.The Meaning of Meaning. C. K. Ogden and I. A. Richards. London: Routledge and Kegan Paul, 1923. 146-152.

Morgan, Jerry L. "Two Types of Convention in Indirect Speech Acts." Syntax and Semantics 9: Pragmatics. Ed. P. Cole. New York: Academic Press, 1978. 261-280.

Nicolle, Steve. "A Relevance-theoretic Account of Be Going To." Journal of Linguistics 33 (1997): 355-377.

"A Relevance-Theoretic Perspective on Grammaticalization." To appear in Cognitive Linguistics (forthcoming).

Searle, John. "Indirect Speech Acts." Syntax and Semantics 3: Speech Acts. Ed. P. Cole and J. Morgan. New York: Academic Press, 1975. 59-82.

Sperber, Dan. Explaining Culture. Oxford: Basil Blackwell, 1996.

Sperber, Dan and Deirdre Wilson. Relevance: Communication and Cognition. Oxford: Basil Blackwell, 1986 (2nd edition 1995).

Sperber, Dan and Wilson, Deirdre. "The Mapping Between the Mental and the Public Lexicon." forthcoming.

Wilson, Deirdre and Dan Sperber. "Linguistic Form and Relevance." Lingua 90 (1993): 1-25.

Žegarac, Vladimir. "What is Phatic Communication?" Paper presented at the 5th IPrA conference, Mexico City, July 1996; to appear in Pragmatics and Beyond New Series. Ed. V. Rouchota and A. Jucker. Amsterdam: John Benjamins (in press).

Žegarac, Vladimir and Billy Clark. "Phatic Interpretations and Phatic Communication." To appear in Journal of Linguistics (forthcoming). 